\title{
Expanded carrier screening using next-generation sequencing of 123 Hong Kong Chinese families: a pilot study
}

\author{
Olivia YM Chan, TY Leung, Y Cao, MM Shi, Angel HW Kwan, Jacqueline PW Chung, KW Choy, \\ SC Chong *
}

\section{A B S T R A C T}

Introduction: To determine the carrier frequency and common mutations of Mendelian variants in Chinese couples using next-generation sequencing (NGS).

Methods: Preconception expanded carrier testing using NGS was offered to women who attended the subfertility clinic. The test was then offered to the partners of women who had positive screening results. Carrier frequency was calculated, and the results of the NGS panel were compared with those of a target panel.

Results: In total, 123 women and 20 of their partners were screened. Overall, 84 (58.7\%) individuals were identified to be carriers of at least one disease, and $68(47.6 \%)$ were carriers after excluding thalassaemias. The most common diseases found were GJB2-related DFNB1 nonsyndromic hearing loss and deafness ( 1 in 4$)$, alpha-thalassaemia ( 1 in 7 ), beta-thalassaemia (1 in 14), 21-hydroxylase deficient congenital adrenal hyperplasia (1 in 13), Pendred's syndrome ( 1 in 36$)$, Krabbe's disease (1 in 48 ), and spinal muscular atrophy (1 in 48). Of the 43 identified variants, 29 (67.4\%) were not included in the American College of Medical Genetics and Genomics or American College of Obstetrics and Gynecology guidelines. Excluding three couples with alpha-thalassaemia, six at-risk couples were identified.
Conclusion: The carrier frequency of the investigated members of the Chinese population was $58.7 \%$ overall and $47.6 \%$ after excluding thalassaemias. This frequency is higher than previously reported. Expanded carrier screening using NGS should be provided to Chinese people to improve the detection rate of carrier status and allow optimal pregnancy planning.

\section{Hong Kong Med J 2021;27:177-83}

https://doi.org/10.12809/hkmj208486

\footnotetext{
1,2 OYM Chan \#, FHKCOG, FHKAM (Obstetrics and Gynaecology)

1,3 TY Leung \#, FRCOG, FHKAM (Obstetrics and Gynaecology)

1,3,4 Y Cao, PhD

${ }^{1}$ MM Shi, MPhil

${ }^{1}$ AHW Kwan, MRCOG

${ }^{1}$ JPW Chung, FHKCOG, FHKAM (Obstetrics and Gynaecology)

${ }^{1,3} \mathrm{KW}$ Choy, PhD

3,4 SC Chong *, FHKCPaed, FHKAM (Paediatrics)
}
Department of Obstetrics and Gynaecology, The Chinese University of Hong Kong, Hong Kong
Adept Medical Centre, Hong Kong.
${ }^{3}$ The Chinese University of Hong Kong-Baylor College of Medicine Joint Center of Medical Genetics, Hong Kong
${ }^{4}$ Department of Paediatrics, The Chinese University of Hong Kong, Hong Kong

* Corresponding author: chongsc@cuhk.edu.hk

\# These authors equally contributed to this work.

New knowledge added by this study

- The carrier frequency of Mendelian variants in the Chinese population is higher than previously reported.

- Next-generation sequencing should be used in the Chinese population to increase the detection rate of carriers of Mendelian variants.

Implications for clinical practice or policy

- Expanded carrier screening with next-generation sequencing should be provided to Chinese people to identify carrier status of Mendelian variants for pregnancy planning.

\section{Introduction}

Carrier screening aims to identify couples at risk of conceiving children affected by recessive genetic diseases. Carrier couples of most recessive genetic conditions are typically asymptomatic, and the only way to identify them is by carrier screening. If a couple are both carriers of the same autosomal recessively inherited condition, their offspring have a 1 in 4 chance of being affected. The risk is as high as 1 in 2 in male offspring if the mother is an X-linked recessive carrier. Carrier screening facilitates informed prenatal testing options such as preimplantation genetic diagnosis, prenatal invasive testing, and other reproductive options such as donor gametes and adoption for carrier couples. Prenatal genetic diagnosis could provide parents 


\section{透過次世代基因檢測123個家庭進行擴展帶因者 測試：先導研究 \\ 陳耀敏、梁德楊、曹也、史蒙蒙、關凱尹、鍾佩樺、 蔡光偉、莊淑貞}

引言 : 使用次世代基因檢測確定華籍夫婦中孟德爾變體的帶因者頻率 和常見突變。

方法 : 利用次世代基因檢測為生育指導診所就診的女性提供孕前擴展 帶因者測試, 然後為篩查結果呈陽性的女性伴侶提供相關測試。計算 帶因者頻率並將次世代基因檢測結果與標靶基因組結果進行比較。

結果：共篩選 123 名婦女及其當中的 20 名伴侶。總體而言, 84 人 ( $58.7 \%$ ) 為至少一種疾病的帶因者, 排除地中海貧血後的帶因者有 68 人 $(47.6 \%)$ 。最常見疾病是GJB2 基因相關的DFNB 1 非綜合徵型 聽力缺損及喪失 $(1 / 4)$ 、甲型地中海貧血 $(1 / 7)$ 、乙型地中海貧血 （1/14）、缺乏21-羥化酶引致的先天性腎上腺增生症 $(1 / 13)$ 、耳 聾一甲狀腺腫綜合（1/36）、嬰兒家族性濔漫性硬化（1/48）以及脊 髓性肌肉萎縮症（1/48）。在43種已鑑定變異中, 有 29 種 $(67.4 \%)$ 未包含在美國醫學遺傳學與基因組學學院或美國婦產科學院指南中。 除了三對患有地中海貧血的夫婦，還確定了六對高危夫婦。

結論：研究對象的總體帶因者比例為 $58.7 \%$, 剔除地中海貧血後的帶 因者比例則為 $47.6 \%$, 較以往報告為高。應擴展華籍人口次世代基因 檢測節查，以提高帶因者檢出率並制定最理想的生育計劃。 with more information, appropriate counselling, and preparation to take care of the child. ${ }^{1}$

Various carrier screening programmes targeting specific populations have been developed for single gene diseases such as cystic fibrosis, thalassaemia, and Tay-Sachs disease. ${ }^{2,3}$ The American College of Obstetrics and Gynecology (ACOG) published guidelines on ethnically based carrier screening programmes, eg, screening for haemoglobinopathies in individuals of Southeast Asian, African and Mediterranean descent and screening for cystic fibrosis, Tay-Sachs disease, familial dysautonomia, and Canavan disease for individuals of Ashkenazi Jewish descent. ${ }^{2,4}$ However, race and ethnicity can only be determined by patient self-report, and measures to ascertain ethnicity are restrictive. ${ }^{5}$ Ancestry-based screening could also lead to unequal distribution of genetic testing and may miss diagnosis of diseases in populations without screening. ${ }^{3}$ Thus, both the American College of Medical Genetics and Genomics (ACMG) and ACOG recommended carrier screening for cystic fibrosis in all couples in 2001. ${ }^{6,7}$ The ACMG and ACOG have also recommended carrier screening for spinal muscular atrophy (SMA) in all couples since 2008 and 2017, respectively. ${ }^{8,9}$

With advancements in genomic technology providing access to next-generation sequencing (NGS), expanded screening panels that cover a wide variety of disorders could be offered to individuals regardless of ethnic background. ${ }^{9}$

The common mutations in the screening panel are mainly chosen based on studies performed in the Caucasian and Ashkenazi Jewish populations. Those known common mutations may not be ethnicityspecific and may not cover all mutations present in the Chinese population. Thus, the approach of sequencing the entire disease-causing gene would be more useful than the targeted common mutations approach for the Chinese population.

Studies that evaluate carrier frequencies and common mutations in the Chinese population are lacking in our locality. Further study to review carrier frequency and the identified variants in the Chinese population is essential to guide the future design of carrier screening platforms specific to the Chinese population and improve the cost-effectiveness of carrier screening for genetic diseases.

\section{Methods}

\section{Subjects}

Expanded carrier screening testing was offered to women who attended the subfertility clinic and pre-pregnancy counselling clinic of the study unit between March 2016 and March 2017. They were counselled about the prevalence and inheritance of recessive conditions, and the chance of having affected offspring for a silent carrier couple, using examples and figures. The purpose, testing methods, interpretation of results, potential benefits, risks, and limitations of the expanded carrier screening were also explained.

A generic consent form for the expanded carrier screening testing prepared by the laboratory was used. Consent for the use of data obtained for research or audit purposes was also obtained. The test was then ordered by the clinician as selffinanced testing. The expanded carrier screening test was offered to both members of the couple separately during pre-test counselling. During posttest counselling, if a woman was identified to be a carrier of an autosomal recessive disease, but her partner had not completed the test, her partner was also counselled for carrier testing using the same method as self-financed testing. If both the male and female members of the couple were carriers of a same autosomal recessive disorder or the female was the carrier of an X-linked recessive disorder, they were identified as at-risk couples having the possibility of an affected pregnancy. Genetic counselling was arranged for at-risk couples to discuss reproductive options such as preimplantation genetic testing and prenatal diagnostic testing. Finally, the carrier frequencies of individual diseases and the identified variants were reviewed. STROBE reporting guidelines were implemented in this manuscript. 


\section{Disease panels}

The expanded carrier screening panel consisted of 104 conditions inherited in autosomal recessive or $\mathrm{X}$-linked manner (online supplementary Appendix). The severity of these conditions ranged from debilitating diseases with neurological impairment (eg, SMA), reduced lifespan (eg, thalassaemia), or intellectual disability (eg, fragile $\mathrm{X}$ syndrome) to diseases requiring early intervention in the prenatal or early neonatal period (eg, 21-hydroxylase deficient congenital adrenal hyperplasia [CAH]).

\section{Laboratory tests}

The screening platform (Family Prep Screen 2.0; Counsyl, South San Francisco [CA], United States), which was reported by Lazarin et $\mathrm{al}^{10}{ }^{10}$ uses NGS techniques to analyse the listed exons, as well as selected intergenic and intronic regions, of the genes responsible for the recessive conditions. The selected regions were sequenced to high coverage and compared with standards and references of normal variation. High-throughput sequencing detects approximately $94 \%$ of known clinically significant variants according to the test provider. Variants classified as 'predicted' or 'likely' pathogenic have been reported. ${ }^{11}$ Fragile X specific polymerase chain reaction assay was used to determine the CGG repeat size in the $5^{\prime}$ untranslated region of the FMR1 gene. Targeted copy number analysis was used to determine the copy number of exon 7 of the SMN1 gene. g.27134T $>\mathrm{G}$ variant testing for identification of silent SMA carriers is not included in this platform. ${ }^{12}$ The turnaround time of the test was approximately 3 weeks.

\section{Results}

A total of 123 Chinese women (age range, 20-45 years) opted for expanded carrier screening, and $69(56.1 \%)$ of them were found to be carriers of at least one disease. Twenty of the women's partners $(29.0 \%$, 20/69) were willing to complete the screening test after genetic counselling. Screening for possible carrier status before contemplating pregnancy was the indication in all individuals. Excluding one woman who was positive for fragile $\mathrm{X}$ syndrome, 48 women who screened positive opted not to screen their partners. Seventeen of them were solely carriers of alpha- or beta-thalassaemia (10 and 7, respectively), which could be accurately screened by mean corpuscular volume. The results also included 20 GJB2 carriers, especially the c.109G>A (p.Val37Ile) mutation, which has low penetrance and is prevalent in the Chinese population. ${ }^{13,14}$ Carrier status for CAH, SMA, Pendred's syndrome, and other very rare diseases was found in three, one, one, and six individuals, respectively. After integrating partners' data, 84 subjects $(58.7 \%)$ were found to be carriers for at least one recessive disease, including thalassaemias. Excluding thalassaemias, 68 subjects (47.6\%) were found to be carriers of at least one disease (Tables 1 and 2).

TABLE I. Carrier frequency of genetic diseases identified in a cohort of 143 adults, listed according to their frequency and alphabetic order

\begin{tabular}{|c|c|c|}
\hline Disease & $\begin{array}{l}\text { No. }(\%) \text { of } \\
\text { cases identified }\end{array}$ & $\begin{array}{c}\text { Carrier } \\
\text { frequency }\end{array}$ \\
\hline GJB2-related nonsyndromic hearing loss & $40(28.0 \%)$ & 1 in 4 \\
\hline Alpha-thalassaemia & $22(15.4 \%)$ & 1 in 7 \\
\hline $\begin{array}{l}21-\text { Hydroxylase deficient congenital adrenal } \\
\text { hyperplasia }\end{array}$ & $11(7.7 \%)$ & 1 in 13 \\
\hline Beta-thalassaemia & $10(7.0 \%)$ & 1 in 14 \\
\hline Pendred's syndrome & $4(2.8 \%)$ & 1 in 36 \\
\hline Krabbe's disease & $3(2.1 \%)$ & 1 in 48 \\
\hline Spinal muscular atrophy & $3(2.1 \%)$ & 1 in 48 \\
\hline CLN5-related neuronal ceroid lipofuscinosis & $2(1.4 \%)$ & 1 in 72 \\
\hline Fanconi's anaemia type C & $2(1.4 \%)$ & 1 in 72 \\
\hline Biotinidase deficiency & $1(0.7 \%)$ & 1 in 143 \\
\hline Congenital Finnish nephrosis & $1(0.7 \%)$ & 1 in 143 \\
\hline Familial Mediterranean fever & $1(0.7 \%)$ & 1 in 143 \\
\hline Fragile $X$ syndrome & $1(0.7 \%)$ & 1 in 143 \\
\hline Galactosaemia & $1(0.7 \%)$ & 1 in 143 \\
\hline Gaucher's disease & $1(0.7 \%)$ & 1 in 143 \\
\hline Glutaric academia & $1(0.7 \%)$ & 1 in 143 \\
\hline Glycogen storage disease type la & $1(0.7 \%)$ & 1 in 143 \\
\hline GRACILE syndrome & $1(0.7 \%)$ & 1 in 143 \\
\hline Metachromatic leukodystrophy & $1(0.7 \%)$ & 1 in 143 \\
\hline Polyglandular autoimmune syndrome & $1(0.7 \%)$ & 1 in 143 \\
\hline $\begin{array}{l}\text { Glycogen storage disease type II (Pompe's } \\
\text { disease) }\end{array}$ & $1(0.7 \%)$ & 1 in 143 \\
\hline Primary carnitine deficiency & $1(0.7 \%)$ & 1 in 143 \\
\hline Pseudocholinesterase deficiency & $1(0.7 \%)$ & 1 in 143 \\
\hline Walker-Warburg syndrome & $1(0.7 \%)$ & 1 in 143 \\
\hline
\end{tabular}

TABLE 2. Frequency of multiple-disease carriers $(n=143)^{*}$

\begin{tabular}{lcccc}
\hline & $\begin{array}{c}\text { Carrier of at least 1 } \\
\text { disease }\end{array}$ & $\begin{array}{c}\text { Carrier of at least 2 } \\
\text { diseases }\end{array}$ & $\begin{array}{c}\text { Carrier of at least 3 } \\
\text { diseases }\end{array}$ & Carrier of 4 diseases \\
\hline Including thalassaemias & $84(58.7 \%)$ & $24(16.8 \%)$ & $3(2.1 \%)$ & $1(0.7 \%)$ \\
Excluding thalassaemias & $68(47.6 \%)$ & $11(7.7 \%)$ & $1(0.7 \%)$ & 0 \\
\hline
\end{tabular}

* Data are shown as No. (\%) 


\section{Prevalence of carriers of various diseases}

A total of 24 recessive diseases were identified in 84 $(58.7 \%)$ of the 143 subjects. The data are summarised in Table 1. The most common condition identified was GJB2-related hearing loss (frequency: 1 in 4). One subject was also found to be a homozygote for the p.V37I mutation in the GJB2 gene. The subject was aged 34 years and did not complain of hearing impairment at the time of recruitment. Both alphaand beta-thalassaemia were prevalent in this cohort ( 1 in 7 and 1 in 14, respectively), as shown in Table 1. Eleven subjects ( 1 in 13 ) were identified as carriers of the 21-hydroxylase deficient type of CAH. Four subjects were heterozygous carriers of Pendred's syndrome (1 in 36), and three subjects were heterozygous carriers for each of SMA and Krabbe's disease (1 in 48). Two carriers were identified for both CLN5-related neuronal ceroid lipofuscinosis and Fanconi's anaemia type $\mathrm{C}$, and one carrier was identified for each of 15 other recessive conditions (Table 1).

\section{Multiple-disease carriers}

The frequency of multiple-disease carriers is shown in Table 2. Carrier status of at least two recessive conditions was identified in 24 subjects (24/143, $16.8 \%$ ) including thalassaemias and 11 subjects (7.7\%) excluding thalassaemias.

\section{At-risk couples}

One woman was a fragile $\mathrm{X}$ syndrome premutation carrier, and 20 women had positive results for carrier status, and their male partners were sequentially tested. After integrating the sequential testing results, we identified nine at-risk couples, including three of alpha-thalassaemia, two of $\mathrm{CAH}$, two of GJB2-related hearing loss, one of Pendred's syndrome, and one of fragile $\mathrm{X}$ syndrome (Table 3 ). The rate of at-risk couples was $12.0 \%$ (9/75) overall and $8.0 \%(6 / 75)$ excluding thalassaemias.

\section{Comparison between traditional screening guidelines and next-generation sequencing}

Forty three variants were identified by the NGS panel (Table 4). Of the 43 variants, 29 (67.4\%) were not included in the ACMG or ACOG guidelines., ${ }^{9,11}$

\section{Discussion}

This study demonstrated the application of NGS to investigate carrier frequency status of members of the Chinese population in Hong Kong. The overall positive yield of this expanded carrier screening panel in our cohort was $58.7 \%$. Not surprisingly, both alpha- and beta-thalassaemia account for a significant proportion of them. However, even after excluding thalassaemias that could be screened by mean corpuscular volume, the positive yield using NGS was still as high as $47.6 \%$, with 6 out of 75 at-risk couples $(8.0 \%)$ identified and potentially benefiting from further pre-conception genetic counselling.

Although NGS has been increasingly used for genetic carrier screening in Western countries in recent years, there is a scarcity of data about the carrier frequency of various recessive diseases in the Chinese population. In 2013, Lazarin et $\mathrm{al}^{10}$ reported the carrier frequencies of a sample of approximately 20000 people from different ethnic groups using a targeted mutation panel. East Asians had the lowest carrier frequency $(8.5 \%)$ compared with Ashkenazi Jews (43.6\%) or Caucasians (21\%-32.6\%). The most common genetic disease identified among East Asians was GJB2-related hearing loss (1 in 22), followed by beta-thalassaemia/sickle cell disease ( 1 in 78 ) and SMA (1 in 85). However, the assay used by Lazarin et $\mathrm{al}^{10}$ was partially based on targeted genotyping, so carriers of variants other than the included common mutations were not detected. Thus, the reported carrier frequencies are likely underestimated, particularly among East Asians, as the common mutation panel was mainly based on the Caucasian and Ashkenazi Jewish populations.

TABLE 3. Diseases identified in nine at-risk couples

\begin{tabular}{llll}
\hline Couple & Disease & Variants & Family history \\
\hline 1 & Alpha-thalassaemia & SEA, SEA & No \\
2 & Alpha-thalassaemia & SEA, SEA & No \\
3 & Alpha-thalassaemia & SEA, alpha 3.7 & No \\
4 & $\begin{array}{l}21-\text { Hydroxylase deficient congenital } \\
\text { adrenal hyperplasia }\end{array}$ & c.293-13C>G; CYP21A2 deletion & Family history of neonatal \\
death with uncertain cause
\end{tabular}


TABLE 4. Identified variants of recessive diseases

\begin{tabular}{|c|c|c|c|}
\hline Disease & Gene & Variant identified & No. of cases \\
\hline \multirow[t]{3}{*}{ GJB2-related nonsyndromic hearing loss } & \multirow[t]{3}{*}{ GJB2 } & c. $109 \mathrm{G}>\mathrm{A}$ & 35 \\
\hline & & c.235delC & 3 \\
\hline & & c.176_191del & 2 \\
\hline \multirow[t]{5}{*}{ Alpha-thalassaemia } & \multirow[t]{5}{*}{ HBA1/HBA2 } & SEA deletion & 11 \\
\hline & & 3.7 deletion & 6 \\
\hline & & HBA1+HBA2 deletion & 1 \\
\hline & & $4.2 \mathrm{del}$ & 3 \\
\hline & & Haemoglobin Constant Spring & 1 \\
\hline \multirow[t]{5}{*}{ 21-Hydroxylase deficient congenital adrenal hyperplasia } & \multirow[t]{5}{*}{ CYP21A2 } & c. $955 \mathrm{C}>\mathrm{T}$ & 4 \\
\hline & & c. $293-13 C>G$ & 3 \\
\hline & & CYP21A2 deletion & 2 \\
\hline & & c. $1069 \mathrm{C}>\mathrm{T}$ & 1 \\
\hline & & c. $844 \mathrm{G}>\mathrm{T}$ & 1 \\
\hline \multirow[t]{4}{*}{ Beta-thalassaemia } & \multirow[t]{4}{*}{$H B B$} & c.126_129delCTTT & 5 \\
\hline & & c. $316-197 \mathrm{C}>\mathrm{T}$ & 3 \\
\hline & & $-28 A>G$ & 1 \\
\hline & & c. $130 \mathrm{G}>\mathrm{T}$ & 1 \\
\hline \multirow[t]{4}{*}{ Pendred's syndrome } & \multirow[t]{4}{*}{ SLC26A4 } & c. $2168 \mathrm{~A}>\mathrm{G}$ & 1 \\
\hline & & c. $919-2 A>G$ & 1 \\
\hline & & c. $754 \mathrm{~T}>\mathrm{C}$ & 1 \\
\hline & & c. $1160 \mathrm{C}>\mathrm{T}$ & 1 \\
\hline \multirow[t]{2}{*}{ Krabbe's disease } & \multirow[t]{2}{*}{ GALC } & c. $1901 \mathrm{~T}>\mathrm{C}$ & 2 \\
\hline & & c. $946 \mathrm{C}>\mathrm{T}$ & 1 \\
\hline Spinal muscular atrophy & SMN1 & Exon 7 deletion & 3 \\
\hline \multirow[t]{2}{*}{ CLN5-related neuronal ceroid lipofuscinosis } & \multirow[t]{2}{*}{ CLN5 } & c. $595 \mathrm{C}>\mathrm{T}$ & 1 \\
\hline & & c.51delG & 1 \\
\hline \multirow[t]{2}{*}{ Fanconi's anaemia type C } & \multirow[t]{2}{*}{ FANCC } & c. $520 \mathrm{C}>\mathrm{T}$ & 1 \\
\hline & & c.1377_1378delCA & 1 \\
\hline Biotinidase deficiency & $B T D$ & c.637delC & 1 \\
\hline Congenital Finnish nephrosis & NPHS1 & c. $3478 \mathrm{C}>\mathrm{T}$ & 1 \\
\hline Familial Mediterranean fever & MEFV & c. $2282 \mathrm{G}>\mathrm{A}$ & 1 \\
\hline Fragile $X$ syndrome & FMR1 & 29/58 CGG repeats & 1 \\
\hline Galactosaemia & GALT & c. $436 \mathrm{G}>\mathrm{T}$ & 1 \\
\hline Gaucher's disease & $G B A$ & c. $1448 \mathrm{~T}>\mathrm{C}$ & 1 \\
\hline Glutaric acidaemia & $G C D H$ & c. $1240 G>A$ & 1 \\
\hline Glycogen storage disease type la & G6PC & c. $648 \mathrm{G}>\mathrm{T}$ & 1 \\
\hline GRACILE syndrome & BCS1L & c. $493 \mathrm{~A}>\mathrm{T}$ & 1 \\
\hline Metachromatic leukodystrophy & $A R S A$ & c.1344dupC & 1 \\
\hline Polyglandular autoimmune syndrome & AIRE & c. $652+1 \mathrm{G}>\mathrm{T}$ & 1 \\
\hline Glycogen storage disease type II (Pompe's disease) & GAA & c.1411_1414delGAGA & 1 \\
\hline Primary carnitine deficiency & SLC22A5 & c. $1400 C>G$ & 1 \\
\hline Pseudocholinesterase deficiency & $B C H E$ & c.401dup & 1 \\
\hline Walker-Warburg syndrome & FKTN & c. $919 \mathrm{C}>\mathrm{T}$ & 1 \\
\hline
\end{tabular}

In particular, alpha-thalassaemia and $\mathrm{CAH}$ are not carrier prevalence of 415 recessive diseases using included in their panel. Recently, Guo and Gregg ${ }^{15}$ investigated the 120000 samples. The consistent finding is that 
Ashkenazi Jews had the highest carrier frequency (62.9\%), followed by Caucasians, Africans, and Hispanics; South and East Asians had the lowest carrier frequency, but that frequency rose to $32.6 \%$ with a more comprehensive panel. However, because neither alpha-thalassaemia nor SMA was included in the panel, the most common diseases for which carrier status was found among East Asians were autoimmune polyendocrinopathy syndrome type 1 , beta-thalassaemia, Usher's syndrome type IIa, and $\mathrm{CAH}$. The carrier frequency of each of those diseases was $1 \%$ to $2 \%$. In 2018 , Zhao et $\mathrm{al}^{16}$ reported $>10000$ mainland Chinese couples in whom NGS was used to screen for 11 recessive diseases. That study showed a high carrier frequency of $27.49 \%$, and $2.4 \%$ of couples were carriers of the same genetic disease. The authors found that the diseases with the highest carrier frequencies were alpha-thalassaemia (15.1\%), beta-thalassaemia $(4.8 \%)$, phenylketonuria (3.6\%), Wilson's disease (2.0\%), GJB2-related hearing loss (1.7\%), and Pendred's syndrome (1.6\%). However, that study excluded SMA, CAH, and fragile $\mathrm{X}$ syndrome. ${ }^{16}$ Our study's findings are distinguished from those of Lazarin et al, ${ }^{10}$ Guo and Gregg, ${ }^{15}$ and Zhao et $\mathrm{al}^{16}$ in that we observed a much higher carrier rate for GJB2-related hearing loss $(28.0 \%)$, which is consistent with our previous report (15.9\%) using target-enriched massively parallel sequencing..$^{14}$ In addition, we found higher carrier frequencies for $\mathrm{CAH}(7.7 \%)$ and Pendred's syndrome (2.8\%). Our study's observed carrier frequency for SMA (2.1\%) is similar to that found in Western populations, ${ }^{17-21}$ indicating that SMA affects all ethnic groups.

One of the major limitations of our study was the small sample size. More data are required before we can draw precise conclusions regarding the carrier frequency of individual recessive conditions in the Chinese population. Second, patients in this cohort were referred for subfertility or pre-pregnancy counselling for genetic conditions, and give out of this 123-patient cohort had a positive family history, including thalassaemias, balanced translocation carriers, family history of autism, neonatal death, and previous pregnancy with structural abnormality. Thus, some of the results might have been overrepresented. For example, one woman who presented with subfertility was discovered to be a fragile $\mathrm{X}$ permutation carrier, and this may have elevated the carrier frequency of fragile $\mathrm{X}$ in our cohort of 123 women. In our previous study, in which we used a robust polymerase chain reaction-based assay to quantify fragile X CGG repeats for screening of 3000 low-risk Chinese pregnant women, the permutation frequency was approximately 1 in $800 .{ }^{22}$ Another couple in the present study had a previous baby with neonatal death of unknown cause in Mainland China and were found to be 21-hydroxylase deficient $\mathrm{CAH}$ carriers. Nonetheless, even after excluding these two $\mathrm{CAH}$ cases, the CAH carrier frequency in our study (1 in 16) remains high.

Currently, both the ACOG and ACMG recommend carrier screening for SMA and cystic fibrosis only in individuals of East Asian ethnicity. 7,9 If those ethnic-based carrier screening strategies advocated by the guidelines had been followed, many carriers and all five carrier couples identified in our cohort would have been missed. The results of our pilot study suggest that recessive genetic conditions may not be as uncommon as previously thought. Many of the diseases identified in our cohort are debilitating conditions that are associated with progressive neurological derangement and reduced life span, such as SMA, Krabbe's disease, and biotinidase deficiency. More importantly, some conditions such as $\mathrm{CAH}$ may require intervention during the early prenatal or early neonatal periods to avoid irreversible complications. Hence, public and professional awareness of expanded carrier screening should be improved, and genetic counselling and expanded carrier screening should be an option for the Chinese population, especially in the setting of subfertility clinics.

Yet, genetic carrier screening has not been popular among the Chinese population or in Hong Kong because of the high cost of the test and the perceived low carrier rate in Chinese people. As the cost for NGS has dropped recently, and our pilot study demonstrated an overall high yield of $8.0 \%$ of couples at risk of conceiving foetuses with genetic diseases (even after excluding thalassaemias), further studies of couples are warranted. Potential candidates for expanded carrier screening in Hong Kong also include couples in consanguineous marriages, which are common in minor ethnic groups such as Pakistani and Indian. A recent local study showed that they had a higher prevalence of congenital abnormality (10.5\%), unexplained intrauterine fetal demise (4.2\%), and unexplained neonatal death (4.6\%). ${ }^{23}$

In our cohort, NGS was used to analyse the listed exons, as well as selected intergenic and intronic regions, of the genes responsible for certain recessive conditions. The high-throughput sequencing technique was able to detect approximately $94 \%$ of known clinically significant variants irrespective of ethnicity. Of 43 variants identified using NGS, $29(67.4 \%)$ were not included in the ACMG or ACOG guidelines. Thus, our study demonstrated that the NGS technique increased the detection rate of carrier status for recessive conditions in the Chinese population. Yet, further study with a larger sample size should be conducted to study the prevalence of carrier status, which conditions should be included, and ethical issues related to carrier screening testing such as reproductive options. 


\section{Conclusion}

The observed carrier frequency in the Chinese population was $58.7 \%$ overall ( $47.6 \%$ after excluding thalassaemias) and was higher than previously reported. Expanded carrier screening using NGS should be provided to Chinese people to improve the detection rate of carrier status and facilitate optimal pregnancy planning.

\section{Author contributions}

All authors contributed to the concept or design of the study, acquisition of data, analysis or interpretation of the data, drafting of the manuscript, and critical revision of the manuscript for important intellectual content.

All authors had full access to the data, contributed to the study, approved the final version for publication, and take responsibility for its accuracy and integrity.

\section{Conflicts of interest}

As an editor of the journal, JPW Chung was not involved in the peer review process. Other authors have disclosed no conflicts of interest.

\section{Funding/support}

This research project was partially funded by the Liauw's Family Reproductive Genomics Programme.

\section{Ethics approval}

This study obtained ethical approval from The Joint Chinese University of Hong Kong-New Territories East Cluster Clinical Research Ethics Committee (Ref CREC2019.138). All participants gave informed consent before the study.

\section{References}

1. Edwards JG, Feldman G, Goldberg J, et al. Expanded carrier screening in reproductive medicine-points to consider: a joint statement of the American College of Medical Genetics and Genomics, American College of Obstetricians and Gynecologists, National Society of Genetic Counselors, Perinatal Quality Foundation, and Society for Maternal-Fetal Medicine. Obstet Gynecol 2015;125:653-62.

2. ACOG Committee on Obstetrics. ACOG Practice Bulletin No. 78: hemoglobinopathies in pregnancy. Obstet Gynecol 2007;109:229-37.

3. Bajaj K, Gross SJ. Carrier screening: past, present and future. J Clin Med 2014;3:1033-42.

4. ACOG Committee on Genetics. ACOG Committee Opinion No. 442: preconception and prenatal carrier screening for genetic diseases in individuals of Eastern European Jewish descent. Obstet Gynecol 2009;114:950-3.

5. Eisenhower A, Suyemoto K, Lucchese F, Canenguez K. "Which box should I check?": examining standard check box approaches to measuring race and ethnicity. Health Serv Res 2014;49:1034-55.

6. American College of Obstetricians and Gynecologists
Committee on Genetics. ACOG Committee Opinion No. 486: update on carrier screening for cystic fibrosis. Obstet Gynecol 2011;117:1028-31.

7. Watson MS, Cutting GR, Desnick RJ, et al. Cystic fibrosis population carrier screening: 2004 revision of American College of Medical Genetics mutation panel. Genet Med 2004;6:387-91.

8. Prior TW, Professional Practice and Guidelines Committee. Carrier screening for spinal muscular atrophy. Genet Med 2008;10:840-2.

9. Committee on Genetics. Committee Opinion No. 691: carrier screening for genetic conditions. Obstet Gynecol 2017;129:e41-55.

10. Lazarin GA, Haque IS, Nazareth S, et al. An empirical estimate of carrier frequencies for $400+$ causal Mendelian variants: results from an ethnically diverse clinical sample of 23,453 individuals. Genet Med 2013;15:178-86.

11. Haque IS, Lazarin GA, Kang HP, Evans EA, Goldberg JD, Wapner RJ. Modeled fetal risk of genetic diseases identified by expanded carrier screening. JAMA 2016;316:734-42.

12. Feng Y, Ge X, Meng L, et al. The next generation of population-based spinal muscular atrophy carrier screening: comprehensive pan-ethnic SMN1 copy-number and sequence variant analysis by massively parallel sequencing. Genet Med 2017;19:936-44.

13. Shen J, Oza AM, Del Castillo I, et al. Consensus interpretation of the p.Met34Thr and p.Val37lle variants in GJB2 by the ClinGen Hearing Loss Expert Panel. Genet Med 2019;21:2442-52.

14. Choy KW, Cao Y, Lam ST, Lo FM, Morton CC, Leung TY. Target-enriched massively parallel sequencing for genetic diagnosis of hereditary hearing loss in patients with normal array CGH result. Hong Kong Med J 2018;24 Suppl 3:11-4.

15. Guo MH, Gregg AR. Estimating yields of prenatal carrier screening and implications for design of expanded carrier screening panels. Genet Med 2019;21:1940-7.

16. Zhao S, Xiang J, Fan C, et al. Pilot study of expanded carrier screening for 11 recessive diseases in China: results from 10,476 ethnically diverse couples. Eur J Hum Genet 2019;27:254-62.

17. Li C, Geng Y, Zhu X, et al. The prevalence of spinal muscular atrophy carrier in China: evidences from epidemiological surveys. Medicine (Baltimore) 2020;99:e18975.

18. Evans M, McCarthy M, Moore R, Karbassi I, Alagia DP, Lacbawan F. A comprehensive analysis of allele frequencies from 476,930 spinal muscular atrophy test results [23M]. Obstet Gynecol 2019;133:147S.

19. Park JE, Yun S, Roh EY, Yoon JH, Shin S, Ki CS. Carrier frequency of spinal muscular atrophy in a large-scale Korean population. Ann Lab Med 2020;40:326-30.

20. Dejsuphong D, Taweewongsounton A, Khemthong P, et al. Carrier frequency of spinal muscular atrophy in Thailand. Neurol Sci 2019;40:1729-32.

21. Chen X, Sanchis-Juan A, French CE, et al. Spinal muscular atrophy diagnosis and carrier screening from genome sequencing data. Genet Med 2020;22:945-53.

22. Kwok YK, Wong KM, Lo FM, et al. Validation of a robust PCR-based assay for quantifying fragile X CGG repeats. Clin Chim Acta 2016;456:137-43.

23. Siong KH, Au Yeung SK, Leung TY. Parental consanguinity in Hong Kong. Hong Kong Med J 2019;25:192-200. 